\title{
HUMAN RESOURCE MANAGEMENT IN HOSPITALS
}

\author{
Snehal Kumari \\ Scholar, Department of Management, Institute of Management Studies, \\ Devi Ahilya Vishwavidyalaya, Indore, Madhya Pradesh, India
}

\begin{abstract}
Health plays an important role in the successful life of a person. A healthy man can work to his full potential. But an unhealthy person cannot function to his full potential. He has to take leave again and again. Unhealthy people can also prove to be a burden on the economy. If a student is often ill, he is not able to attend school regularly. This has a bad effect on his studies. Later his/her skills are not developed properly and the right employment is not available. If an adult is often ill, he is not able to do his job to the fullest. Therefore, it does not progress with age. Education has an important role in human capital formation. Generally, an educated person is not only more efficient but also earns better. The uneducated person also has an indirect effect on the educated person. To understand this, let us take the example of an engineer. When an engineer is engaged in the construction work, due to that many uneducated people also get employment. The employable skills should be developed of everyone. The current era is the technical and global era, where skills play an important at work place. Human resource management is one of the key aspects of organizational development and growth. In all kinds of organization human resource management plays an important role. There is no excuse to hospitals. Further it is not wrong to say that in Hospital management human resource management plays more important role. Current study is an attempt to focus on Human resource management in hospitals.
\end{abstract}

Key words: Human resource, hospital, management, health, positive attitude, positive approach.

Cite this Article: Snehal Kumari, Human Resource Management in Hospitals, International Journal of Management, 11(12), 2020, pp. 3291-3297.

http://iaeme.com/Home/issue/IJM?Volume=11\&Issue=12

\section{INTRODUCTION}

The concept of raw material is a very broad concept which is even connected with human being also. Just as land, raw materials, equipment, capital, etc. are resources, similarly people are also resources. It is impossible to consume any resource without man's intervention. Therefore, it is said that people are forms of resources. Human resources are quite different as compared to resources like land and physical capital. Education, health and training are required to build 
human resources. Producing from other resources requires currency and physical force. Without interfering with human resources, other resources prove to be useless.

\section{HISTORY OF HUMAN RESOURCE MANAGEMENT IN THE HOSPITALS}

In the year 1961, Dr. JR Mc Gibboni, a consultant in the Hospital Administration field of the World Health Organization, recommended the introduction of hospital administration as a separate specialization, similar to other broad specialization areas of medical science. With this effort in the year 1961-62, a comprehensive program and curriculum for postgraduate courses in hospital administration was drafted. A postgraduate student, an Indian doctor from New South Wales, Australia, was admitted to AIIMS to provide her administration residency. The Australian student completed his dissertation and MD in Hospital Administration in 1962-63. This course of hospital administration was formally approved in 1963-64 and Br. In 1966, under the leadership of (Dr.) Gend, a well-equipped and complete department of hospital administration was started, which became the first-ever Medical Superintendent in India. The current MHA (Postgraduate in Hospital Administration) course was launched in February 1966 and has since been recognized as a distinct postgraduate subject by the Medical Council of India.

The Hospital Administration Department, AIIMS is one of the major departments in India where a Master's degree in Hospital Administration has been introduced. It is the oldest institute in the country to train health managers in the science and art of hospital administration and management. The department introduced the expertise of hospital administration in the country during the year 1962 and has since developed into a centre of excellence for teaching, training and research in the field of hospital administration and management. The department maintains a distinct position in the running and functioning of the AIIMS Hospital Services Division. All the faculty members of the department handle independent charge of hospital administration at the Medical Superintendent level in various patient care centres of the institute. The department regularly conducts training programs for all categories of hospital staff on various aspects of hospital administration and managerial development. In addition, the department runs a 24-hour administrative control room which is a unique concept and serves as an extension of the Office of Medical Superintendents after office hours.

\section{TYPES OF HEALTH CARE UNIT IN INDIA}

There are three healthcare systems prevalent in India which is given in the below image number 1

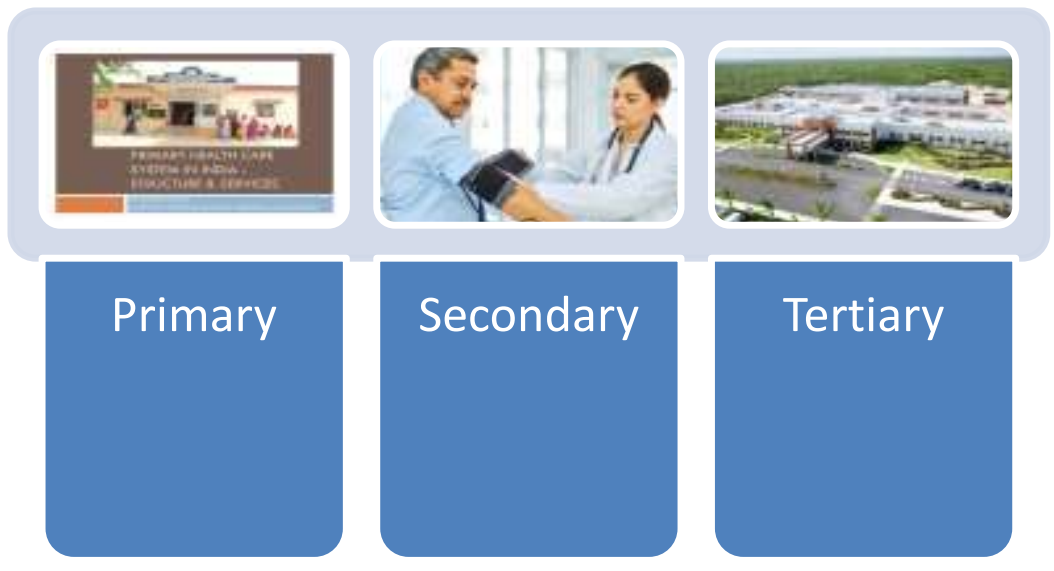

Figure 1 The Types of Health Care Unit in India 
As given in the above image 1, there are main three types of health care unit as primary, secondary and tertiary healthcare systems prevalent in India. Primary health services are provided through sub-centers in rural areas and primary health centers and family welfare centers in urban areas. Secondary health services include district hospitals and community health centers. Hospitals with specific expertise in tertiary healthcare systems come.

The HRM level care of these three levels with their special responsibilities and facilities is given in the below image 2

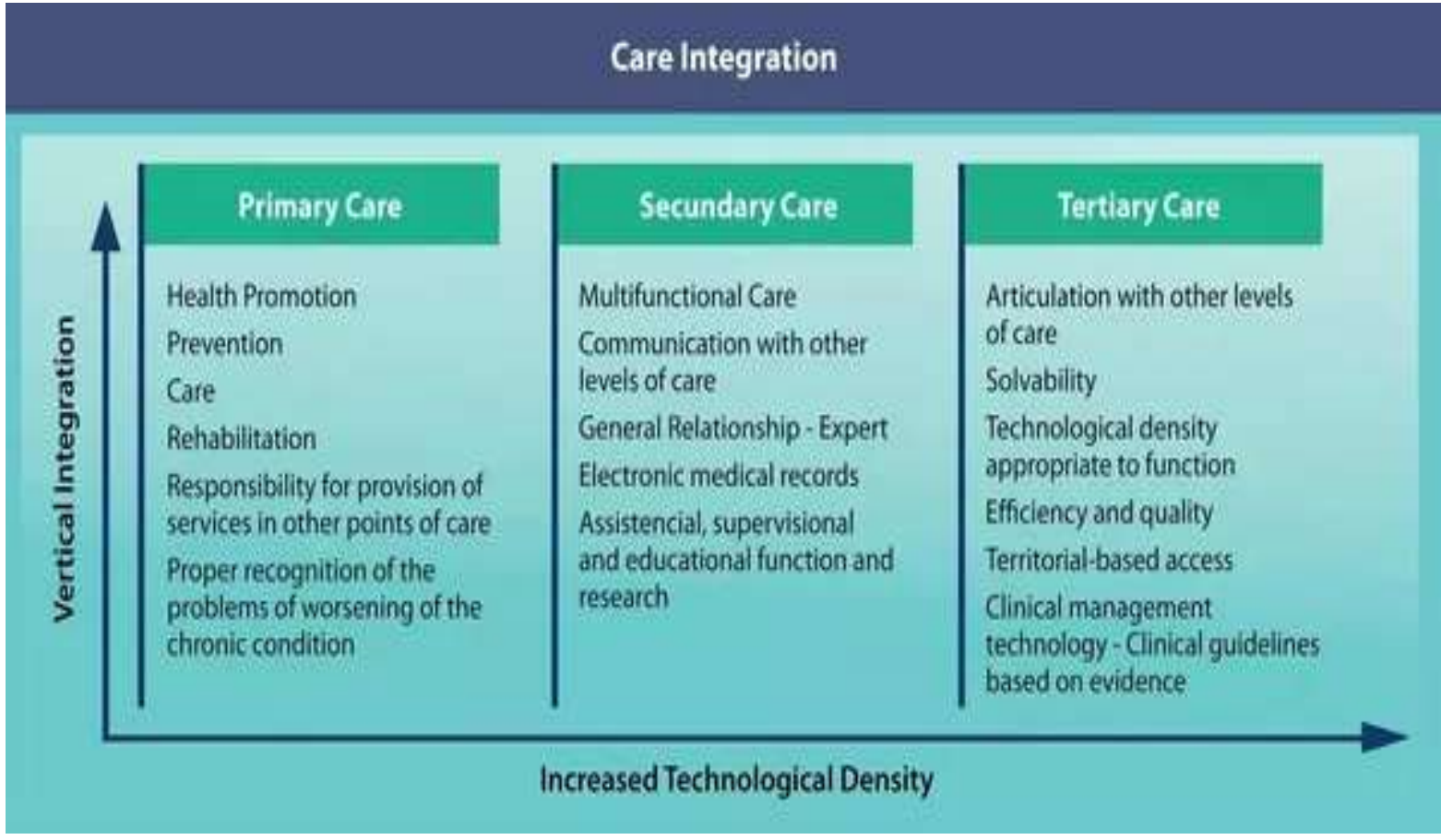

Figure 2 The Care Unit of Hospitals (Source Internet)

As given in the above, the functions of Primary Unit care are health promotion, prevention, care, rehabilitation, responsibility for provision of services in the other points of acre, proper recognition of worsening of the chronic condition. The functions of Secondary care unit of health organizations are multifunctional care, communication with other levels of care, general relationship-expert electronic medical records, Assistencial, supervisional, educational and research function. In the tertiary care unit the functions are as Articulation with other levels of care, Solvability, technological appropriate to functions, efficiency and quality, territorial-based assess, clinical management technology, clinical guidelines based on evidence etc.

To run these three kinds of health care units the following are important aspects of human resource management in the hospitals are given in the below diagram 3:

As given in the image number 1, the following are main aspects of Human Resource Management:

- HR Technology Systems

- workforce planning

- compliance

- benefits

- Payroll

- Organizational Development

- Human Resource Strategy 


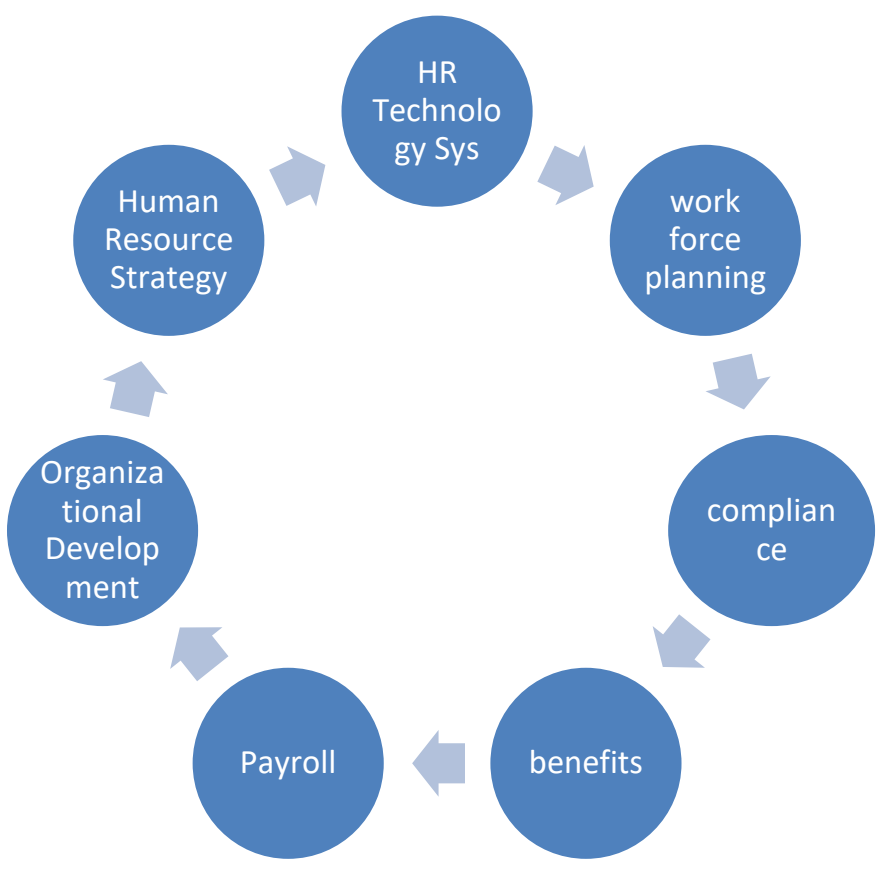

Figure 3 Aspects of Human Resource Management

\section{FUNCTIONS OF HOSPITAL MANAGEMENT}

The hospitals should strongly committed and actively involved in capacity building and human resource development at both levels hospitals i.e. national and international levels hospitals. There are many services which are expected to be provided by hospitals to manage all kinds of human resource connected with hospitals including patients, their relatives and visitors. The following are few important HR services that should be provided by Human Resource Management:

- New health care facility

- Proper Management and planning of HR.

- Health care registration.

- Planning and innovation

- Health care human resource management,

- Disaster management

- Hospital equipment planning and management

- Health care funding and insurance product development

- To impart, to give, to promote and to preserve knowledge and skills to HRM connected with hospital management.

- To integrate in learning methods includes lectures, case analysis, simulation exercises, syndicates, group discussions and practical project tasks.

- To develop conceptual, analytical and decision-making skills.

- To improve quality in training, teaching and research in the field of hospital administration.

Thus, human resource management (HRM) engages in the development of standards for BIS, including various categories of hospitals, and serves as a consideration group to formulate national health care policy guidelines. Resident doctors are encouraged to participate actively in decision making activities operating in various activities of the institute. It prepares them to 
work independently in real-life management of hospitals and health care facilities. The performance of the resident is continuously assessed through direct observation and faculty feedback system. In pursuit of excellence in teaching and training of hospital administration, the department has made an effort to develop model curriculum to meet the changing demands and skill requirements of this field. Efforts are on to bring quality standards.

\subsection{Practices and Policies Human Resource Management in the Hospitals}

Human resource management refers to the practices and policies needed to carry out the personnel aspects of management such as:

- To analyze the jobs and its nature

- To Plan for the manpower needs

- To recruit competent people

- To select best people

- To analyze the appraising performance

- To analyze potential of employees of hospitals on ongoing basis

- To socialize, train and develop people with best skills to deal with HR

- To Manage compensation for people

- To develop the Communication skills of people

- To building employee commitment

As a pioneering step in this direction, the department is the first department in the country to receive ISO 9001: 2000 Quality Management System Certification documentation of its teaching, training, research and patient care management processes. Efforts are underway to improve health care processes by motivation and leadership, and to provide hospital administration education in the nation and the South East Asian region.

\subsection{The Basic Requirements in Human Resource Management in the Hospitals}

\subsubsection{Expenditures on Human Resource Management}

According to the study, huge expenditure in health services is spent on salaries and other payment systems and very little amount are left for basic facilities like medicines and disease detection. About 53 percent of the total expenditure of hospitals is spent on human resources, while only 14 percent is spent for medicines and other facilities.

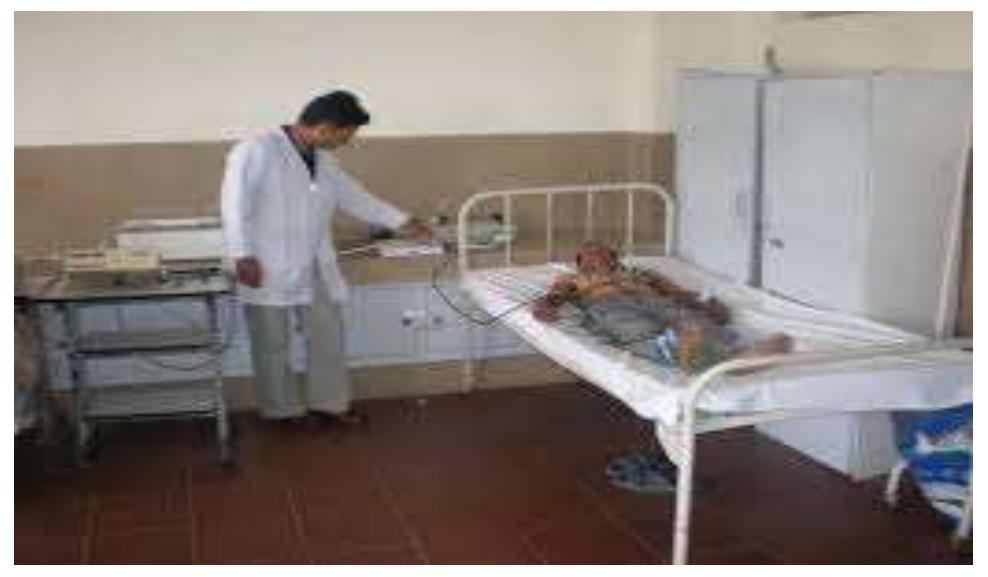

Figure 4 Picture of Physical Facility in the Hospital 
The study, conducted by researchers from Sharma Institute of Postgraduate Medical Sciences and Dr. Rajendra Prasad Government Medical College, Kangra, has been published in the research journal Indian Journal of Medical Research.

As shown in the above image number 1.4, investment in health services needs to be widely focused. Health services should have effective human resource management policy and principles in place with professionalism, accountability and fairness. According to the researchers, in district hospitals of North India, very little is spent on the clinical analysis required to identify essential medicines and diseases. The situation is such that most of the mandatory lives saving medicines are not available in these hospitals. In such cases patients are not able to get proper treatment and they go under stress. Rather than having treatment more critical health issues may be a cause due to lack of improper physical facilities in the hospital.

The total annual expenditure on secondary level health services in district hospitals of North India is estimated to be around Rs 11.5 crore. A hospitalization for one day costs Rs 844 per patient, Rs 3,481 per operation and Rs 170 for outpatient counselling.

The researchers believe that investment in health services needs to be widely focused. Health services should have effective human resource management policy and principles in place with professionalism, accountability and fairness. At the same time, secondary level health services also need to be strongly integrated with primary health services, so that better health services can be provided with adequate resources including infrastructure, human resources and medicines and equipment.

The study also emphasizes the need to massively determine minimum spending for drugs and other clinical analysis facilities. According to the researchers, this study can be helpful in understanding the limitations of hospitals and increasing their efficiency. Existing estimates can be revised and cost estimates can be made using the findings of this study also for proper expenditure management of health services. They can also help in performing cost-effective analysis of various health services.

The majority of the country's population is dependent on district hospitals and community health centres. But the condition of the district hospitals can be gauged from this that 53 percent of the total expenditure on these is spent on human resources and the supply of medicines and other essential equipment is neglected.

This has emerged in a recent study conducted by Indian researchers. The researchers have found that the health services in these hospitals are not satisfactory due to lack of resources. Researchers have reached this conclusion after examining the expenditure on secondary health services in public district hospitals in North India during the study.

\subsubsection{Staffing and Recruitment}

In the HRM management of hospital for the proper treatment of patients, the physical facilities are important so as the staffing is also very important which includes Staffing, human resources planning and forecasting, recruiting, and selecting employees. The process which is firm uses to ensure that it has the right amount and the right kind of people to deliver a particular level of output or services in the future is called as Human resources planning and forecasting process. The process which used to form a pool of job candidates for a particular job is called as the Recruitment process. Selection is the process of making a "hire" or "no hire" decision regarding each job applicant for a job.

\subsection{Barriers in the Proper Human Resource Management in the Hospital}

There are many barriers in Human Resource Management; few of them are given below:

- To select the wrong person for the right job in the hospital. 
- To expense high employee turnover.

- To find people not contributing their best for the hospital.

- Very Poor time management.

- To Having company taken to court because of discriminatory practices

- Dissatisfied employees/ No job satisfaction

- Failure to provide job related training

- To indulge the favouritism and nepotism at the cost of organizational effectiveness.

\section{CONCLUSION}

Thus, Human resource management is very crucial job because in this sector the matter of life and death is deal by all kinds of human being including serving people to experts doctors, patients to their neighbours and visitors including physicians, nursing professionals, pharmacists, midwives, dentists, allied health professions, community health workers, social health workers and other health care providers. They all are engaged in the field of health human resources with issues such several activities such as planning, development, performance, management, retention, information, and research on human resources for the health care sector. Some are involved directly in health care unit or some are indirectly. Now-a-days, there are many raising awareness issues of the critical role of HRH to strengthen the health system performance as well as to improve the health of people.

\section{REFERENCES}

[1] Compendium of tools and guidelines for HRH situation analysis, planning, policies and management systems

[2] Dal Poz, MR; et al., eds. (2009). "Handbook on monitoring and evaluation of human resources for health". World Health Organization. Geneva.

[3] Dreesch, N; et al. (September 2005). "An approach to estimating human resource requirements to achieve the Millennium Development Goals". Health Policy and Planning. 20 (5): 267-276. doi:10.1093/heapol/czi036. PMID 16076934.

[4] Grépin, Karen A; Savedoff, William D (November 2009). "10 Best Resources on ... health workers in developing countries". Health Policy and Planning. 24 (6): 479-482. doi:10.1093/heapol/czp038. PMID 19726562.

[5] "Global Health Observatory (GHO) data: Health workforce". World Health Organization. Geneva. Retrieved 8 August 2017.

[6] Human Resources for Health Databases, Canadian Institute for Health Information

[7] Human resources for health in developing countries - a dossier from the Institute for Development Studies

[8] "Health human resources planning" (PDF). International Council of Nurses. Geneva. 2008.

[9] Scheffler, RM; et al. (2011). "Human resources for mental health: workforce shortages in lowand middle-income countries" (PDF). World Health Organization. Geneva.

[10] World Health Organization programme of work on health human resources 